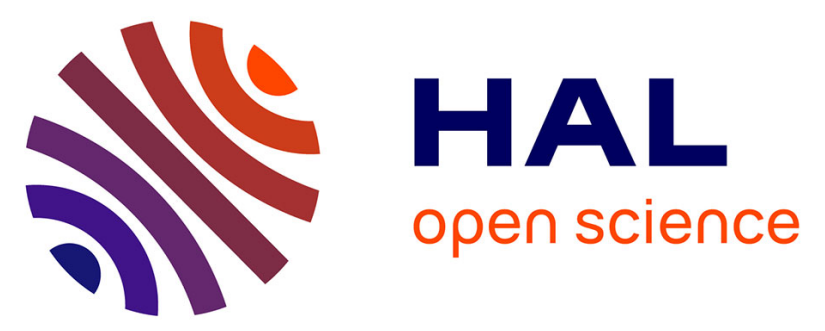

\title{
The Impacts of Demand Response on the Efficiency of Energy Markets in the Presence of Wind Farms
}

\author{
Neda Hajibandeh, Miadreza Shafie-Khah, Saber Talari, João Catalão
}

\section{To cite this version:}

Neda Hajibandeh, Miadreza Shafie-Khah, Saber Talari, João Catalão. The Impacts of Demand Response on the Efficiency of Energy Markets in the Presence of Wind Farms. 8th Doctoral Conference on Computing, Electrical and Industrial Systems (DoCEIS), May 2017, Costa de Caparica, Portugal. pp.287-296, 10.1007/978-3-319-56077-9_28. hal-01629597

\section{HAL Id: hal-01629597 https://hal.inria.fr/hal-01629597}

Submitted on 6 Nov 2017

HAL is a multi-disciplinary open access archive for the deposit and dissemination of scientific research documents, whether they are published or not. The documents may come from teaching and research institutions in France or abroad, or from public or private research centers.
L'archive ouverte pluridisciplinaire HAL, est destinée au dépôt et à la diffusion de documents scientifiques de niveau recherche, publiés ou non, émanant des établissements d'enseignement et de recherche français ou étrangers, des laboratoires publics ou privés. 


\title{
The Impacts of Demand Response on the Efficiency of Energy Markets in the Presence of Wind Farms
}

\author{
Neda Hajibandeh ${ }^{1}$, Miadreza Shafie-khah ${ }^{1}$, Saber Talari ${ }^{1}$ and João P.S. Catalão $0^{1,2,3}$ \\ ${ }^{1}$ C-MAST, University of Beira Interior, Covilhã 6201-001, Portugal \\ 2 INESC TEC and the Faculty of Engineering of the University of Porto, Porto 4200-465 \\ ${ }^{3}$ INESC-ID, Instituto Superior Técnico, University of Lisbon, Lisbon 1049-001, Portugal \\ hajibandeh.n@ubi.pt; miadreza@ubi.pt; saber.talari@ubi.pt; catalao@fe.up.pt
}

\begin{abstract}
In this paper, an optimal scheduling of thermal and wind power plants is presented by using a stochastic programming approach to cover the uncertainties of the forecasted generation of wind farms. Uncertainties related to wind forecast error, consequently wind generation outage power and also system load demand are modeled through scenario generation. Then, with regard to day-ahead and real-time energy markets and taking into account the relevant constraints, the thermal unit commitment problem is solved considering wind energy injection into the system. Besides, in order to assess impacts of Demand Response (DR) on the problem, a load reduction demand response model has been applied in the base model. In this approach, self and cross elasticity is used for modeling the customers' behavior modeling. The results indicate that the DR Programs (DRPs) improves the market efficiency especially in peak hours when the thermal Gencos become critical suppliers and the combination of DRPs and wind farm can be so efficient.
\end{abstract}

Keywords: Demand Response, Electricity Market, Stochastic programming, Wind production.

\section{Introduction}

Different countries have increased contribution of renewable energy resources by planning and applying protectionist policies of renewable energies [1]. In some countries, wind sources participate in the electricity markets disregarding imbalance penalties [2]. Imbalance penalties are defined as power planned by supplier minus generated power. It is used for security and appropriate utilization of system and avoids to be trifled with market. In some power markets, wind resources will be allowed to offer energy in the market, but some of supportive methods are used to increase their income. These methods usually increase power imbalance in the time of use and thereupon, will follow increasing the cost for the system [3].

In [4], a changeable tariff method has been used to specify income of wind power unit in the power market. In the current method, the consumption cost rises in proportion to its increase and therefore, more consumption is not associated with more subsidy and high consumption customers are in the focus of rising cost instead 
of whole customers. In [5, 6], the method of profit maximization is used to participate wind power plants. Modelling of uncertainties is necessary for these methods. Also, since the interval between time of bidding and time of use may be high, wind power plant's income will be reduced in these methods. A supportive method for contribution of wind power plant to the power markets has been discussed in [7]. However, if the content of wind resources increases, use of supportive methods will be inefficient.

In this paper, two-stage stochastic bidding considering uncertainty in the market price is carried out. Uncertainty in the market price is modelled as probability density function and finally, each renewable generating unit presents a set of its strategies as probability density function. Among the presented models for estimation of wind speed, Weibull distribution has the best fitting for statistical data, so in most articles it is used as a suitable distribution to estimate the wind speed [8-9]. Appropriate values for parameters estimation of this probability function accepted for wind speed have been given in [10-11].

In the current paper, the aim is to model players' behavior in the imperfect market and obtain the optimum point to tariff the DRPs, while the scope of research is from the perspective of independent system operator (ISO). A model is proposed for day-ahead and real-time energy markets with implementation of DRPs in presence of the wind turbines. In fact, system uncertainties including outage of wind farms are merged in a two-stage stochastic model.

The remainder of this paper is structured as follows. Relationship to smart systems is provided in section 2. In section 3, modelling the wind power units in the market is introduced and their mathematical model is presented. Numeric results of the model are presented in section 4 , and the last section concludes the paper.

\section{Relationship to Smart Systems}

With the expansion of smart meters, like Advanced Metering Infrastructure (AMI) and Internet of Things (IoT), in demand side of power systems, implementation of different methods of DR is going to be much more applicable [11]. A suitable DR method can not only decrease total operation cost but also provide security and safety of the network operation [12].

In [13], DR is discussed considering wind units connected to a smart grid. They have tried to maximize the social welfare while the intermittent nature of wind may impose some real challenges. It is performed a comparison with the predictable scheduling and with a non-smart grid. The proposed approach balances the wind power fluctuations in the grid due to DR management.

In continuous we proposed DR programs as well to mitigate the challenges of grid including wind units. 


\section{The Proposed Model}

In the current paper, the price-based DRP, Time of Use (TOU) [14, 15], is considered. Equation (1) denotes the optimal customer's demand in 24 hours while taking part in price-based DRPs [16].

$$
d(t)=d_{0}(t)\left\{1+\sum_{t^{\prime}=1}^{24} E\left(t, t^{\prime}\right) \cdot \frac{\left[\rho\left(t^{\prime}\right)-\rho_{0}\left(t^{\prime}\right)\right]}{\rho_{0}\left(t^{\prime}\right)}\right\}
$$

where $d(t)$ and $d_{0}(t)$ are the final and initial electricity demand, respectively. $\rho_{0}(t)$ and $\rho_{0}(t)$ are the final and initial electricity tariffs, respectively. $E\left(t, t^{\prime}\right)$ represents the elasticity of demand. Considering to a guaranteed purchase of electricity from the renewable resources including wind and solar, in many studies and planning, renewable loads are considered as negative loads when setting the market prices based on offer for sale of all power plants. In addition to, in some markets, these renewable resources can also bid their price in the power market and sell their energy as thermal and other power plants.

But, according to the policy makings of the governments to encourage and attract investor toward generating electricity from the renewable energies and developing clear energies in the countries, they usually purchase the electricity of clear resources from the vendors at prices several times the market clearing price to make an incentive to attract investors to this industry and guarantee to purchase the electricity at high and fixed price [17].

The unit commitment program and its aggregate constraints can be modeled as below:

$$
\begin{aligned}
& \text { Minimize } \\
& \sum_{t=1}^{N T} \sum_{i=1}^{N G}\left(S U C_{i, t}+M P C_{i} U_{i, t}+\sum_{m=1}^{N M}\left(P_{i, t, m}^{e} C_{i, t, m}^{G_{-} E n g}\right)\right)+\sum_{t=1}^{N T} \sum_{i=1}^{N G} C_{i, t}^{G_{-} U C} R_{i, t}^{G_{-} U C}+C_{i, t}^{G_{-} D C} R_{i, t}^{G_{-} D C} \\
& +\sum_{t=1}^{N T} \sum_{w=1}^{N W} \rho_{w}\left(\sum_{i=1}^{N G} C_{i, t}^{G_{-} U E} r_{i, t, w}^{G_{-} u p}-C_{i, t}^{G_{-} D E} r_{i, t, w}^{G_{d} d n}\right)
\end{aligned}
$$

where $P_{i, t, m}^{e}$ denotes the production of segment $m$ in a linear form of cost function. $C_{i, t, m}^{G_{-} E n g}$ is the slope of each segment. $C_{i, t}^{G_{-} D C}$ and $C_{i, t}^{G_{-} U C}$ are the offered price of downand up-reserves of power producers. $C_{i, t}^{G_{-} U E}$ and $C_{i, t}^{G_{-} D E}$ represent the offered price of up- and down- deployed reserves of each unit. $R_{i, t}^{G_{-} U C}$ and $R_{i, t}^{G_{-} D C}$ the scheduled upand down-reserve capacities of each unit, respectively. $r_{i, t, w}^{G, u p}$ and $r_{i, t, w}^{G-d n}$ represent the real-time up- and down- deployed reserves of each unit. $S U C_{i, t}$ denotes the start-up cost. $M P C_{i} U_{i, t}$ is the minimum production cost. The costs of start-up, minimum generation, and the electricity of producer plants are included in the objective function. The second part of the objective function is associated with the offer price of 
up/down reserve from production plants. The next term consists of the scenarios consideration. The prices with regard to the expected delivered up/down reserve through production plants are formulated in the next term. The scenarios of wind power are generated based on a roulette wheel mechanism presented in [18]. The objective function is subjected to following constraints.

\subsection{Day-Ahead Equations}

Equation (3) guarantees the demand-supply balance. As regard with modelling the linearized transmission limits, DC load flow is used as formulated through (4). Furthermore, the branch limitations are modelled in (5). Wind units considered in the day-ahead session are constrained due to the predicted wind production in (6). Electricity and capacity equations of thermal plants are proposed in (7)-(11). Block electricity output of thermal plants and the limits are described through (7). Equations (8)-(9) restrain the generation of thermal plants. The reserve up/down limits are described in (10)-(11) as well. The inequality (12) denotes the start-up limit of thermal plants. Constraints (13) and (14) formulate the minimum up/down times of thermal plants, respectively [19].

$$
\begin{aligned}
& \sum_{i \in G_{b}} P_{i t}+\sum_{w f \in W F_{b}} P_{w f, t}^{W P, S}-\sum_{j \in J_{b}} L_{j, t}^{C}=\sum_{l \in L_{b}} F_{l, t}^{0} \quad \forall b, t \\
& F_{l, t}^{0}=\left(\delta_{b, t}^{0}-\delta_{b^{\prime}, t}^{0}\right) X_{l} \quad \forall l, t \\
& -F_{l}^{\max } \leq F_{l, t}^{0} \leq F_{l}^{\max } \quad \forall l, t \\
& 0 \leq P_{w f, t}^{W P, S} \leq P_{w f, t}^{W P, \max } \quad \forall w f, t \\
& P_{i, t}=\sum_{m=1}^{N M} P_{i, t, m}^{e}, 0 \leq P_{i, t, m}^{e} \leq P_{i, m}^{\max } \quad \forall i, t \\
& P_{i, t}+R_{i, t}^{G-U C} \leq P_{i}^{\max } \quad \forall i, t \\
& P_{i, t}-R_{i, t}^{G-D C} \geq 0 \quad \forall i, t \\
& 0 \leq R_{i, t}^{G, U C} \leq R U_{i} \tau \quad \forall i, t \\
& 0 \leq R_{i, t}^{G-D C} \leq R D_{i} \tau \quad \forall i, t \\
& S C_{i, t} \geq S C_{i}\left(U_{i, t}-U_{i, t-1}\right) \quad \forall i, t \\
& \sum_{t^{\prime}=t+2}^{t+M U T_{i}}\left(1-U_{i, t^{\prime}}\right)+M U T_{i}\left(U_{i, t}-U_{i, t-1}\right) \leq M U T_{i} \quad \forall i, t \\
& \sum_{t+M D T_{i}}^{t+U_{i, t}} U_{t^{\prime}=t+2}+M D T_{i}\left(U_{i, t-1}-U_{i, t}\right) \leq M D T_{i} \quad \forall i, t
\end{aligned}
$$




\subsection{Real-Time Equations}

This stage is dealing with fulfilling the limits in the realization of all scenarios. The demand-supply balance is taken into account for all the scenarios in (15) by considering the updates of wind generation. Constraints (16)-(17) are similar to (4)-(5) that consider for all the scenarios. The delivered up/down reserve in all scenarios needs to be limited to the planned reserve capacity formerly submitted to the markets (18)(19). Constraint (20) characterizes the net generation of thermal plants in real-time. Equation (21) represents the technical constraints of thermal generators. Ramp up/down limit is given in (22)-(23).

$$
\begin{aligned}
& \sum_{i \in G_{b}}\left(r_{i, w, t}^{G \_u p}-r_{i, w, t}^{G \_d n}\right)+\sum_{w f \in W F_{b}}\left(P_{w f, w, t}^{W}-P_{w f, t}^{W P, S}\right)=\sum_{l \in L_{b}} F_{l, w, t}-F_{l, t}^{0} \quad \forall b, w, t \\
& F_{l, w, t}=\left(\delta_{b, w, t}-\delta_{b^{\prime}, w, t}\right) / X_{l} \quad \forall l, w, t \\
& -F_{l}^{\max } \leq F_{l, w, t} \leq F_{l}^{\max } \quad \forall l, w, t \\
& 0 \leq r_{i, w, t}^{G \_u p} \leq R_{i, t}^{G \_U C} \quad \forall i, w, t \\
& 0 \leq r_{i, w, t}^{G \_d n} \leq R_{i, t}^{G \_D C} \quad \forall i, w, t \\
& P_{i, w, t}=P_{i, t}+r_{i, w, t}^{G \_u p}-r_{i, w, t}^{G-d n} \quad \forall i, w, t \\
& P_{i}^{\min } U_{i, t} \leq P_{i, w, t} \leq P_{i}^{\mathrm{max}} U_{i, t} \quad \forall i, w, t \\
& P_{i, w, t}-P_{i, w, t-1} \leq R U_{i} U_{i t}+S U R_{i}\left(1-U_{i, t-1}\right) \forall i, w, t \\
& P_{i, w, t-1}-P_{i, w, t} \leq R D_{i} U_{i, t-1}+S D R_{i}\left(1-U_{i, t}\right) \forall i, w, t
\end{aligned}
$$

\section{Numerical Results of the Model}

In order to indicate the impact of DRPs on the oligopolistic behavior of electricity market in presence of wind farm, the IEEE six-bus test system is employed [20]. The mixed-integer linear programming has been modeled in GAMS 24.0 and solved by CPLEX 12.0. In addition different types of TOU programs are studied as presented in Table 1 . It is assumed that $20 \%$ of consumers are responsive demand except the TOU3 tariff that its price tariff is considered as the same as TOU-1 but at this program $40 \%$ of consumers are responsive demand.

The impact of different types of TOU programs on Genco 1 is compared with the generation in base case without the presence of wind farm and in presence of the wind units, the power output of Genco 1 in these cases are presented in Fig. 1 and Fig. 2, respectively. According to Fig. 1, Genco 1 is affected by the load shifting arisen from TOU tariffs. On this basis, the generation in valley period is increased based on the 
low tariff, while the generation reduces in the peak period. Fig. 2 depicts the same great affection but the very considerable and beneficial changes in base case in presence of wind units. As it is shown there is a comprehensive reform in the curve and chart. It should be noted that the prices in base case program is obtained from the simulation of the electricity market without implementation of DRPs. In the base case, the average of market prices is considered as electricity tariff in all hours. In TOU programs, the mentioned tariff is considered as the tariff in off-peak hours. The self- and cross-elasticities are extracted from [21].

Table 1. Tariffs/incentives of considered DRPs (€/MWH)

\begin{tabular}{l|l|c|c|c}
\hline Case & $\begin{array}{l}\text { Valley } \\
(1 \text { to } 8)\end{array}$ & $\begin{array}{c}\text { Off- } \\
\text { peak. } \\
(9- \\
11,22-24)\end{array}$ & $\begin{array}{c}\text { Peak. } \\
(12-14 \\
, 19-21)\end{array}$ & $\begin{array}{c}\text { Critical } \\
\text { peak } \\
\text { (15 to 18) }\end{array}$ \\
\hline Base case (fixed-rate) & 63.2 & 63.2 & 63.2 & 63.2 \\
\hline TOU-1 & 31.6 & 63.2 & 94.8 & 94.8 \\
\hline TOU-2 & 15.8 & 63.2 & 126.4 & 126.4 \\
\hline TOU-3 & 31.6 & 63.2 & 94.8 & 189.6 \\
\hline
\end{tabular}

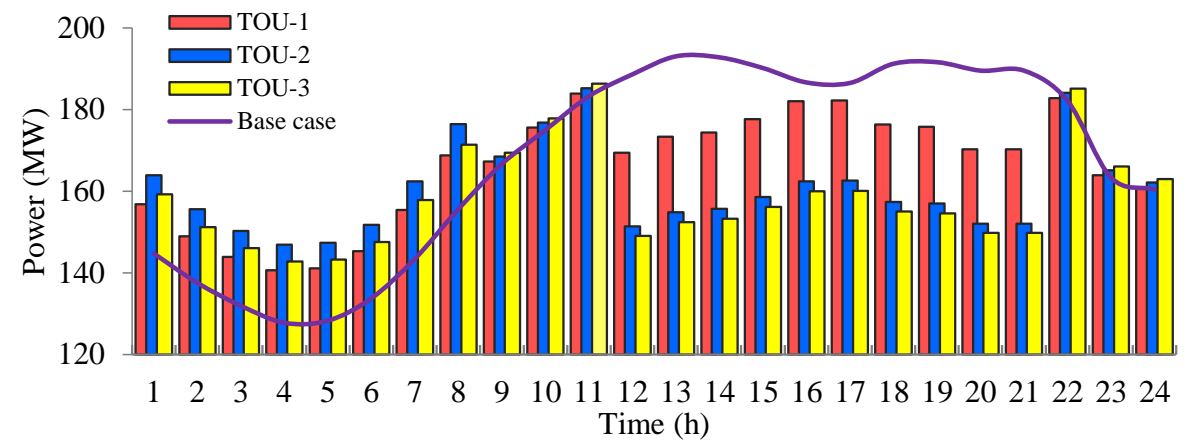

Fig. 1. Impact of different types of TOU program on the generation of Genco 1 without the presence of wind farm. 


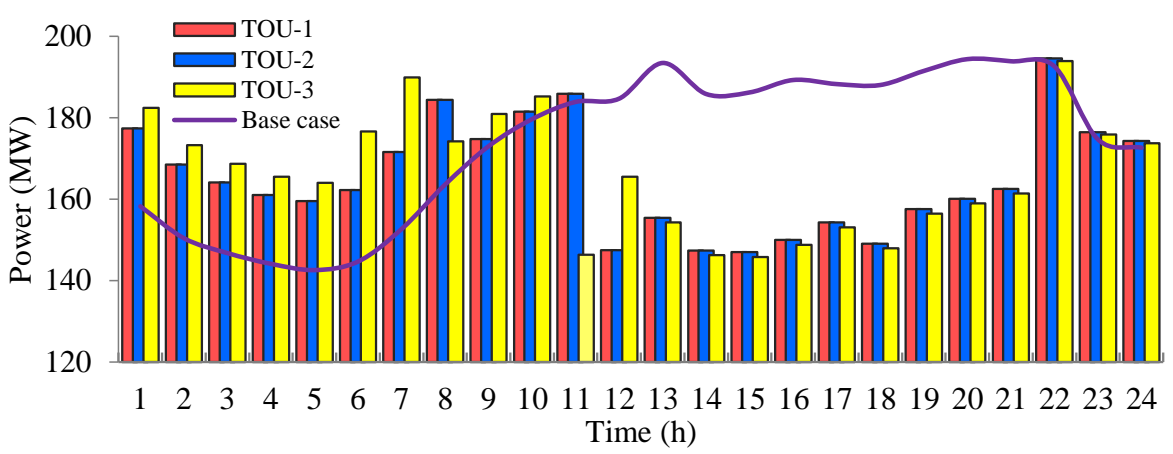

Fig. 2. Impact of different types of TOU program on the generation of Genco 1 in the presence of wind farm.

Developing the investigation of the impact of different types of TOU programs on the behaviour of market players Figs. 3 and 4 are presented. These figures depict the power output of Genco 2 without the presence of wind farm and in presence of the wind units respectively. These results show the different tariffs of TOU demand response in presence of wind farm can more considerably effect on shifting peak loads to Valley. Fig. 3 shows the significant impact of TOU programs on the electricity market prices in the peak period, because of the reduction of offered prices of the system's Gencos. The impact of different types of TOU programs on objective function is presented in Table 2. As it is expected, it shows that total price after implementation of DRPs with presence of wind farm is less than that in the system with no renewable units.

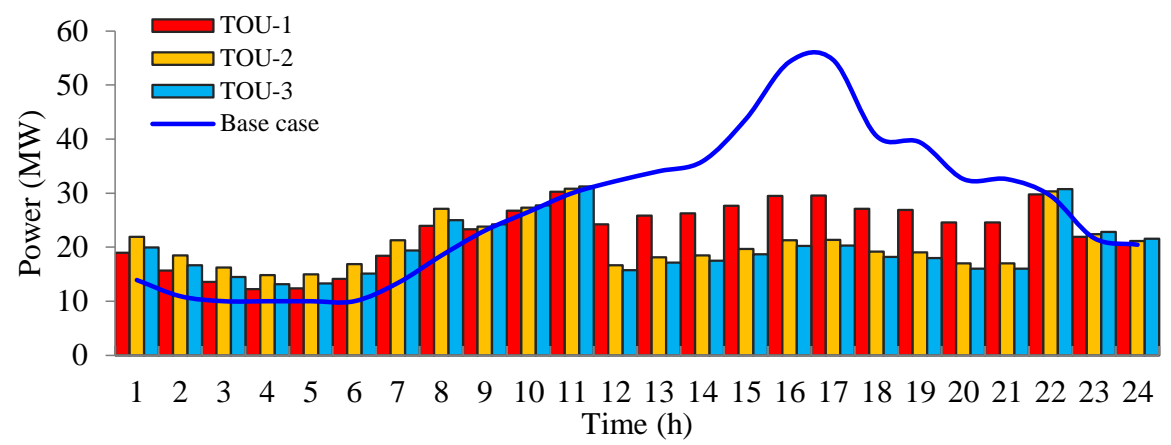

Fig. 3. Impact of different types of TOU program on the generation of Genco 2 without the presence of wind farm. 


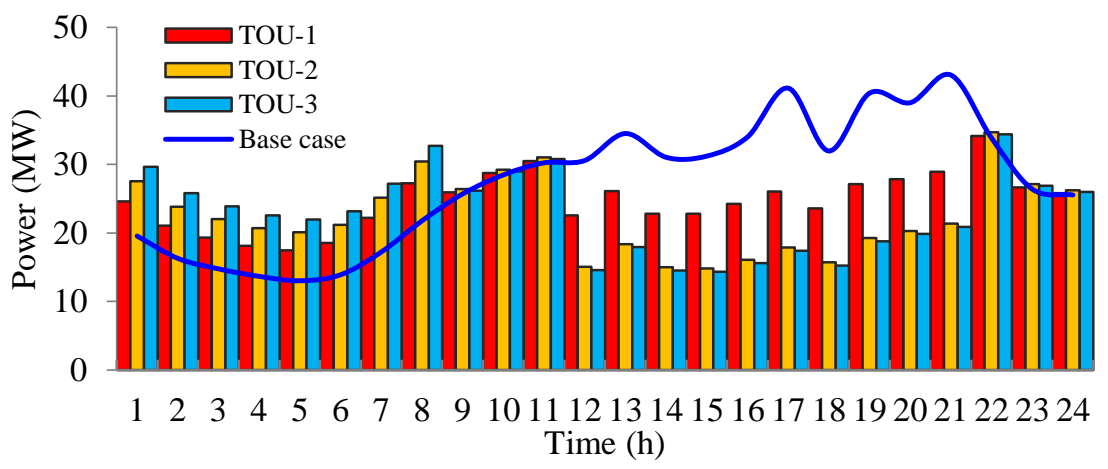

Fig. 4. Impact of different types of TOU program on the generation of Genco 2 in the presence of wind farm.

Table 2. Total cost for different DRPs in compere of presence or absence of wind farm

\begin{tabular}{l|c|c}
\hline Case & $\begin{array}{l}\text { Without considering } \\
\text { the wind units in the } \\
\text { system }\end{array}$ & $\begin{array}{c}\text { With considering the } \\
\text { wind units in the system }\end{array}$ \\
\hline Base case (fixed-rate) & $2.0935 \mathrm{E}+5$ & $2.0036 \mathrm{E}+5$ \\
\hline TOU-1 & $1.9799 \mathrm{E}+5$ & $1.8994 \mathrm{E}+5$ \\
\hline TOU-2 & $1.8692 \mathrm{E}+5$ & $1.7940 \mathrm{E}+5$ \\
\hline TOU-3 & $1.8886 \mathrm{E}+5$ & $1.8153 \mathrm{E}+5$ \\
\hline
\end{tabular}

\section{Conclusions}

In this paper, modelling the power market was conducted and bidding of power plants and making the supply curve and then its intersection with the demand curve to find clearing price of market were modelled. Next, the impacts of uncertainty of wind farms outages on electricity price were investigated by modelling them as negative loads. Lower electricity prices reduced profits from the sale of electricity for thermal power plants that had higher utilization cost and made them reduce their motivation to take part in the electricity markets.

Regarding the unstable nature of wind energy and the problem of market price reduction in the case of wind energy, the impact of a demand response program on such a system was studied. In other words, finally by adding the demand response planning to the models, the electricity market and approach to the real condition were studied. The presence of both the wind energy and demand response program led to lower prices and provided price adjustment and market stability. 
Acknowledgment. This work was supported by FEDER funds through COMPETE 2020 and by Portuguese funds through FCT, under Projects SAICT-PAC/0004/2015 POCI-01-0145-FEDER-016434, POCI-01-0145-FEDER-006961, UID/EEA/50014/2013, UID/CEC/50021/2013, and UID/EMS/00151/2013. Also, the research leading to these results has received funding from the EU Seventh Framework Programme FP7/2007-2013 under grant agreement no. 309048.

\section{References}

1. Kennedy, J., Fox, B., Flynn, D.: Use of electricity price to match heat load with wind power generation. Proc. of the IEEE Conference on Sustainable Power Generation \& Supply (2009).

2. Bathurst, G.N., Weatherrill, J., Strbac, G.: Trading wind generation in short-term energy markets. IEEE Trans. Power Syst. 17, 782-789 (2002).

3. Matevosyan, J., Söder, L.: Minimization of imbalance cost trading wind power on the shortterm power market, IEEE Trans. Power Syst. 21, 1396-1404 (2006).

4. Wang $\mathrm{Yu}$, et al: Valuation of switchable tariff for wind energy. Electric Power Systems Research. 76, 382-388 (2006).

5. Pinson, P., Chevallier, C., Kariniotakis, G.: Trading wind generation from short-term probabilistic forecasts of wind power. IEEE Trans. Power Syst. 22, 1148-1156 (2007).

6. Morales, J.M., Conejo, A. j., Perez-Ruiz , J.: Short-Term Trading for a Wind Power Producer. IEEE Trans. Power Syst. 25, 554-564 (2010).

7. Parsa Moghadm, M., Talebi, E., Mohamadian, M.: A new method for pricing of wind power in short-term power markets. presented at 16th Power Systems Computation Conference (PSCC) (2008).

8. Moeini-Aghtaie, M., Abbaspour, A., Fotuhi-Firuzabad, M.: Incorporating large-scale distant wind farms in probabilistic transmission expansion planning-Part I: Theory and algorithm. IEEE Transactions on Power Systems. 27, 1585-1593 (2012).

9. Kianoosh, G., Boroojeni, M., Amini, H., Bahrami, H., Iyengar, S.S., Arif, I., Karabasoglu, O.: A novel multi-time-scale modeling for electric power demand forecasting: From shortterm to medium-term horizon. Electric Power Systems Research. 142, 58-73 (2017).

10.Yu, H., et al.: Probabilistic load flow evaluation with hybrid latin hypercube sampling and cholesky decomposition. IEEE Transactions on Power Systems. 24, 661-667(2009).

11.Verbic, G., Schellenberg, Rosehart, A.W and Canizares, C.A.: Probabilistic Optimal Power Flow Applications to Electricity Markets. In Probabilistic Methods Applied to Powe Systems (PMAPS) (2006).

12.Boroojeni , K. G., Amini, M. H., Iyengar, S.S.: Overview of the Security and Privacy Issues in Smart Grids. Smart Grids. Security and Privacy Issues. Springer International Publishing (2017).

13.Çiçek, N., Deliç, H.: Demand Response Management for Smart Grids With Wind Power. IEEE Transactions on Sustainable Energy. 6, 625-634 (2015).

14.Heydarian-Forushani, E., Golshan, M. E. H., Moghaddam, M. P., Shafie-khah, M., Catalão, J. P. S.: Robust scheduling of variable wind generation by coordination of bulk energy storages and demand response. Energy Conversion and Management, 106, 941-950 (2015).

15.Heydarian-Forushani, E., Golshan, M. E. H., Shafie-khah, M.: Flexible security-constrained scheduling of wind power enabling time of use pricing scheme. Energy. 90, 1887-1900 (2015).

16.Arasteh, H. et al.: Iot-based smart cities: A survey. IEEE 16th International Conference on Environment and Electrical Engineering (EEEIC) (2016). 
17.Aalami, H.A., Moghaddam, M.P., Yousefi, G.R.: Demand response modeling considering Interruptible/Curtailable loads and capacity market programs. Applied Energy (2010).

18.Shafie-khah, et al.: Strategic offering for a price-maker wind power producer in oligopoly markets considering demand response exchange. IEEE Trans Industrial Informatics, 11(6), $1542-1553$ (2015).

19.Shafie-khah, M., Moghaddam, M. P., Sheikh-El-Eslami, M. K.: Unified solution of a nonconvex SCUC problem using combination of modified branch-and-bound method with quadratic programming. Energy Conversion and Management, 52(12), 3425-3432 (2011).

20.Fu, Y., Shahidehpour , M., and Li, Z.: AC contingency dispatch based on securityconstrained unit commitmen. IEEE Trans Power Systems. 21, 897-908 (2006).

21.Zhao, C., Wang, J.: Multi-Stage Robust Unit Commitment considering Wind and Demand Response. IEEE Trans Power Systems. 1-10 (2013). 